\title{
Antioxidant capacities of the selenium nanoparticles stabilized by chitosan
}

\author{
Xiaona Zhai ${ }^{1}$, Chunyue Zhang ${ }^{1}$, Guanghua Zhao' ${ }^{1}$ Serge Stoll², Fazheng Ren ${ }^{1}$ and Xiaojing Leng ${ }^{1 *}$
}

\begin{abstract}
Backgrounds: Selenium (Se) as one of the essential trace elements for human plays an important role in the oxidation reduction system. But the high toxicity of Se limits its application. In this case, the element Se with zero oxidation state $\left(\mathrm{Se}^{0}\right)$ has captured our attention because of its low toxicity and excellent bioavailability. However, $\mathrm{Se}^{0}$ is very unstable and easily changes into the inactive form. By now many efforts have been done to protect its stability. And this work was conducted to explore the antioxidant capacities of the stable $\mathrm{Se}^{0}$ nanoparticles (SeNPs) stabilized using chitosan (CS) with different molecular weights (Mws) (CS-SeNPs).

Results: The different Mws CS-SeNPs could form uniform sphere particles with a size of about $103 \mathrm{~nm}$ after 30 days. The antioxidant tests of the DPPH, ABTS, and lipid peroxide models showed that these CS-SeNPs could scavenge free radicals at different levels. And the 1 month old SeNPs held the higher ABTS scavenging ability that the value could reach up to $87.45 \pm 7.63 \%$ and $89.44 \pm 5.03 \%$ of CS(I)-SeNPs and CS(h)-SeNPs, respectively. In the cell test using BABLC-3T3 or Caco-2, the production of the intracellular reactive oxygen species (ROS) could be inhibited in a Se concentration-dependent manner. The topical or oral administration of CS-SeNPs, particularly the Se nanoparticles stabilized with low molecular weight CS, CS(I)-SeNPs, and treated with a 30-day storage process, could efficiently protect glutathione peroxidase (GPX) activity and prevent the lipofusin formation induced by UV-radiation or D-galactose in mice, respectively. Such effects were more evident in viscera than in skin. The acute toxicity of CS(I)-SeNPs was tenfold lower than that of $\mathrm{H}_{2} \mathrm{SeO}_{3}$.
\end{abstract}

Conclusions: Our work could demonstrate the CS-SeNPs hold a lower toxicity and a 30-day storage process could enhance the antioxidant capacities. All CS-SeNPs could penetrate the tissues and perform their antioxidant effects, especially the CS(I)-SeNPs in mice models. What's more, the antioxidant capacities of CS-SeNPs were more evident in viscera than in skin.

Keywords: Chitosan, Selenium nanoparticles, ROS, Lipofuscin, UV radiation, D-Galactose

\section{Background}

Selenium (Se) is involved in the antioxidant defense systems of the liver and plays an important role in protecting against oxidative stress. Many studies demonstrated that Se supplementation can increase the level of enzymes such as GPx etc., prevent the accumulation of free radical species, and reduce the cellular damage [1-4]. However, the narrow margin between the effective and toxic doses

\footnotetext{
${ }^{*}$ Correspondence: lengxiaojingcau@163.com

1 Beijing Advanced Innovation Center for Food Nutrition and Human Health, Beijing Laboratory for Food Quality and Safety, Beijing Dairy Industry Innovation Team, College of Food Science \& Nutritional Engineering, China Agricultural University, Beijing 100083, China Full list of author information is available at the end of the article
}

limited the application of this substance [5]. The $\mathrm{Se}^{0}$ has thus gained more attention because of its low toxicity and excellent bioavailability compared with $\mathrm{Se}(\mathrm{IV})$ and $\mathrm{Se}(\mathrm{VI})$, since both having a strong ability to capture free radicals [6,7]. Nevertheless, poor water solubility and the ability to easily transform into a grey analogue that is thermodynamically stable but biologically inert, makes $\mathrm{Se}^{0}$ difficult to be used in food and medicine fields $[8,9]$.

The water solubility of an insoluble substance can be greatly improved by reducing the size and increased the specific surface with convenient nanotechnology. In the past decades, nanotechnology has been used to prepare antioxidant products using minerals including silver [10], gold [11], cerium oxide [12], and platinum [13] etc., based 
upon their red-ox abilities. Selenium was also considered owing its multiple valence states $(+6,+4,+2,0,-1,-2)$ and more complex antioxidant activities [14]. In a quest to use $\mathrm{Se}^{0}$, many efforts have been made to design such nano-vehicles using polysaccharides, proteins, and/or lipids etc. as stabilizers [15-17]. The obtained Se nanoparticles are reported as novel compounds with excellent antioxidant properties and lower toxicity compared with other selenospecies [18]. It should be noted that in these reports the data about the effects of the stabilizers on the antioxidant functionalities of the nanosystem are still incomplete, especially on the relationships between the microstructure features and bio-activities of the whole system in vitro and in vivo.

Chitosan (CS), the N-deacetylated form of natural chitin found widely in the exoskeleton of crustaceans, insects, and fungi, has been often used as the $\mathrm{Se}^{0}$-stabilizer not only because of its low toxicity and bioavailability, but it can also withstand pepsin and pancreatin to a great extent $[19,20]$. This naturally helps to enhance the stability of the $\mathrm{Se}^{0}$ system in the digestive enzyme environment. In our previous work, we compared the physicochemical properties of the $\mathrm{Se}^{0}$ spherical nanoparticles with a size at about $103 \mathrm{~nm}$ prepared through the reduction of seleninic acid with ascorbic acid in the presence of chitosan with different molecular weights [21]. We found that, although SeNPs could be stabilized using both the chitosan with low [CS(l)-SeNPs] or high molecular weight $[\mathrm{CS}(\mathrm{h})-\mathrm{SeNPs}]$ in 30 days, the microstructure of the former seemed more compact than the latter. This divergence caused the Se release of the former more slowly than the latter in the simulated gastric, intestinal, and sweat environment. This raises a question as to whether such difference in the microstructure of SeNPs between CS(l)-SeNPs and CS(h)-SeNPs affects the bioactivities of these nanoparticles in vitro and in vivo.

As side-products of the normal metabolism, the accumulation of random molecular damage due to ROS promoted by oxidative stress is widely believed to cause cellular aging [22]. Lipofusin (LF) as the hallmark of aging is a membrane-bound cellular waste by oxidation that can be neither degraded nor ejected from the cell but can only be diluted through cell division and subsequent growth which is often found in skin and viscera [23-25]. In spite of LF formation involving complex intracellular reactions, it can be retarded by various antioxidant systems including enzymatic (e.g., GPx, SOD, etc.) and nonenzymatic antioxidant systems (e.g., vitamins $\mathrm{E}$ and $\mathrm{C}$ etc.) [26]. Many works pointed out that the level of the GPx activity could represent the state of Se uptake [3]. In addition, some reports indicated that a low status of Se was related with LF accumulation, and topical and oral Se administration of L-selenomethionine or sodium selenite could prevent LF formation induced by UV irradiation [27-29]. Therefore, the detection of GPx activity and LF levels can be used to study the antioxidant activities of CS-SeNPs.

In this work, CS-SeNPs were manufactured using chitosan with different molecular weights and with different storage times according to our previous work [21]. The inhibition of the intracellular ROS by CS-SeNPs was examined in the BABLC-3T3 and Caco-2 cell lines, designed as skin or viscera cell models, respectively. The former cell has been scientifically validated for the skin phototoxicity test [30], and the latter can represent drug intestinal absorption. The effects of CS-SeNPs on LF in skin and viscera were investigated using mice models treated with UV-radiation and D-galactose, respectively. The concerned acute toxicity of the nanoparticles was also verified.

\section{Methods \\ Reagents}

The seleninic acid $\left(\mathrm{H}_{2} \mathrm{SeO}_{3}\right)$, 2,2'-Azino-bis(3-ethylbenzothiazoline-6-sulfonic acid (ABTS), 2,2-Diphenyl-1-picrylhydrazyl (DPPH), D-(+)-galactose, reduced L-glutathione (buffered aqueous solution, $\geq 10$ units/mg protein, recombinant, expressed in E. coli), 2,3-Diaminonaphthalene (DAN), 2',7'-Dichlorofluorescein diacetate (DCFH-DA), 2,4,6-Tris(dimethylaminomethyl) phenol(DMP-30), and glutaraldehyde were purchased from Sigma Aldrich, Inc. (St. Louis, MO, USA). Dulbecco's Modified Eagle Medium (DMEM), fetal bovine serum, Penicillin-Streptomycin Solution $(100 \times)$, GlutaMAXTM-1 $(100 \times)$, MEM Nonessential Amino Acid Solution (NEAA, 100 $\times$ ), dimethyl sulfoxide (DMSO), potassium phosphate (PBS, pH 7.4), Trypsin-EDTA, formalin, hematoxylin, and eosin were purchased from Solarbio Science \& Technology Co., Ltd. (Beijing, China). The chitosan with a molecular weight of less than $3 \mathrm{kDa}$ (CS3) and $200 \mathrm{kDa}$ (CS200) (Poly- $\beta$ - $(1,4)$ D-glucosamine, DD $>85 \%$ ) were purchased from Jinan Haidebei Co., Ltd. (Shandong, China). The other regents included acetic acid, ascorbic acid, $\mathrm{HClO}_{4}, \mathrm{HNO}_{3}, \mathrm{HCl}$, $\mathrm{H}_{2} \mathrm{SO}_{4}$, EDTA, ethanol, methanol, acetone, cyclohexane, potassium persulfate $\left(\mathrm{K}_{2} \mathrm{~S}_{2} \mathrm{O}_{8}\right), \mathrm{Na}_{2} \mathrm{HPO}_{4} \cdot 12 \mathrm{H}_{2} \mathrm{O}$, $\mathrm{NaH}_{2} \mathrm{PO}_{4} \cdot 2 \mathrm{H}_{2} \mathrm{O}$, egg lecithin, $\mathrm{FeSO}_{4}$, trichloroacetic acid (TCA), 2-Thiobarbituric acid (TBA), $\mathrm{NaCl}$, hydroxylamine hydrochloride, cresol red, quinine sulphate, ammonium hydroxide, stearic acid, white petrolatum, propylene glycol, triethanolamine, and edetate disodium dehydrate were of analytical grade. The edible oil, wax, and rosin were from the local market.

\section{Preparation and characterization of CS-SeNPs}

CS-SeNPs were manufactured according to the method described in our previous work [21]. These nanoparticles 
stabilized with CS3 and CS200 were denoted as CS(l)-SeNPs and CS(h)-SeNPs, respectively. The numbers 0 and 30 in CS(l)-SeNPs-0 day, CS(l)-SeNPs-30 days, CS(h)-SeNPs-0 day, and $\mathrm{CS}(\mathrm{h})$-SeNPs-30 days were used to distinguish the nanoparticles manufactured immediately and those followed by 30-days storage, respectively. The Se concentration of all of the CS-SeNPs stock was adjusted to $0.1 \mathrm{~mol} / \mathrm{L}$.

The morphology of these nanoparticles was observed by means of scanning transmission electron microscopy (STEM). The sample solution was dropped on a carboncoated copper grid for $5 \mathrm{~min}$ and the excess solution was removed and dried in the air for $30 \mathrm{~min}$. The observations were performed using a Hitachi S-5500 STEM (Hitachi High Technologies America, Inc. IL, USA) with an operation voltage of $30 \mathrm{kV}$. The images were acquired using a Gatan high-angle annular bright field scintillating detector. The hydrodynamic size and zeta potential of the nanoparticles were measured using a Delsa-Nano Particle Analyzer (A53878, Beckman Coulter, Inc., CA, USA).

\section{Assay for antioxidant activities of CS-SeNPs in vitro}

The antioxidant abilities of the CS-SeNPs samples were presented as the radicals scavenging activity (RSC\%) in DPPH, ABTS, or lipid peroxide. The value of RSC\% was calculated using the following formula:

$$
\operatorname{RSC}(\%)=\frac{\mathrm{A}_{0}-\mathrm{A}_{1}}{\mathrm{~A}_{0}} \times 100 \%
$$

where $A_{0}$ is the absorbance of the control and $A_{1}$ is the absorbance of the mixed solution of the antioxidant and free radical agent.

The RSC\% in DPPH was determined according to the method described in the work of $\mathrm{Xu}$ [31]. A $0.2 \mathrm{~mL}$ dose of the nanoparticle sample was mixed vigorously with $3.8 \mathrm{~mL}$ of DPPH radical ethanol solution (final DPPH concentration: $0.1 \mathrm{mmol} / \mathrm{L}$ ), and then kept at room temperature in the dark for $30 \mathrm{~min}$. The absorbance was measured at $517 \mathrm{~nm}$ with a UV spectrophotometer (UVmini-1240; Shimadzu, Japan).

The $\mathrm{RSC} \%$ in ABTS was determined according to the work of Re [32]. The stock was prepared by mixing $0.5 \mathrm{~mL}$ of $14 \mathrm{mmol} / \mathrm{L}$ ABTS and $0.5 \mathrm{~mL}$ of $4.9 \mathrm{mmol} / \mathrm{L} \mathrm{K}_{2} \mathrm{~S}_{2} \mathrm{O}_{8}$, and then keeping them in the dark at room temperature for at least $12 \mathrm{~h}$ in a $1.5 \mathrm{~mL}$ tube. The absorbance of the ABTS solution was adjusted by PBS buffer (pH 7.4, $150 \mathrm{mmol} / \mathrm{L}$ ) to $0.70 \pm 0.02$ at $734 \mathrm{~nm}$. The measurement was performed at $734 \mathrm{~nm}$ exactly $4 \mathrm{~min}$ after mixing $900 \mu \mathrm{L}$ of the diluted ABTS solution with $100 \mu \mathrm{L}$ of the nanoparticle sample.

A modified TBA-reactive species assay was used to measure the formed lipid peroxide with egg yolk lecithin homogenates as a lipid-rich media [33]. The occurrence of malondialdehyde (MDA), a secondary end product of the oxidation of polyunsaturated fatty acids, was used as an index of lipid peroxidation. The MDA reacted with TBA to yield a pinkish-red chromogen with an absorbance maximum at $532 \mathrm{~nm}$. One gram of egg lecithin was

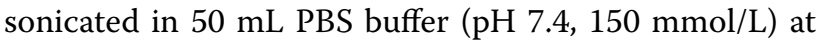
$4{ }^{\circ} \mathrm{C}$ for $30 \mathrm{~min}$. After mixing $0.5 \mathrm{~mL}$ of this solution with $0.1 \mathrm{~mL}$ of the nanoparticle sample, the total volume was made up to $1 \mathrm{~mL}$ with distilled water. The obtained mixture was added into $0.05 \mathrm{~mL}$ of $\mathrm{FeSO}_{4}(70 \mathrm{mmol} / \mathrm{L})$ and then incubated at $37^{\circ} \mathrm{C}$ for $30 \mathrm{~min}$. We added $0.5 \mathrm{~mL}$ of TCA $(10 \%, w / w)$ into the above incubated solution, followed by $0.5 \mathrm{~mL}$ of TBA $(1 \%, \mathrm{w} / \mathrm{w})$. The final mixture was vortexed and heated in a boiling water bath for $60 \mathrm{~min}$. After cooling, the solution was centrifuged at $3000 \times g$ for $10 \mathrm{~min}$. The upper organic layer was collected and measured at $532 \mathrm{~nm}$.

\section{Cell lines and culture}

Two types of cell lines, purchased from China Infrastructure of Cell Line Recourses (Beijing, China), were used in this work. One was the mouse embryonic fibroblast BABLC 3T3 cells cultured in DMEM media supplemented with $10 \%(\mathrm{v} / \mathrm{v})$ bovine calf serum and $1 \%(\mathrm{v} / \mathrm{v})$ GlutaMAX, and the other was Caco-2 cells cultured in DMEM containing $10 \%(\mathrm{v} / \mathrm{v})$ bovine calf serum and $1 \%$ (v/v) NEAA. Both cell lines were incubated at $37^{\circ} \mathrm{C}$ in a humidified incubator with $5 \% \mathrm{CO}_{2}$.

\section{Cell viability assay}

The MTT assay was used to determine the cytotoxicity of the CS-NPs [18] and a MTT [3-(4, 5-dimethylthiazol2-yl)-2, 5-diphenyltetrazolium bromide] cell viability/ cytotoxicity assay kit (Beyotime Biotechnology, Jiangsu, China) was used to determine cell viability. Healthy cells can reduce the MTT to a purple formazan dye. Both cells were seeded in a 96-well microplate with $5 \times 10^{3}$ cell/ well and $0.1 \mathrm{~mL}$ growth medium/well for $24 \mathrm{~h}$, respectively. After that, each cell line was treated by incubating with $\mathrm{CS}(\mathrm{l})$-SeNPs, CS(h)-SeNPs, and $\mathrm{H}_{2} \mathrm{SeO}_{3}$, respectively. The Se concentrations varied between 50 and 500 $\mu \mathrm{mol} / \mathrm{L}$. The incubation was performed for another $24 \mathrm{~h}$. The control groups were left untreated. The absorbance was measured at $570 \mathrm{~nm}$ with a Thermo Fisher Scientific Varioskan ${ }^{\circledR}$ Flash Multimode Reader (Thermo Scientific, USA); the viability was determined based on the manufacturer's instructions.

\section{Measurement of the intracellular ROS generation}

The intracellular ROS accumulation was evaluated using a DCF fluorescence assay [34]. The BABLC-3T3 and Caco- 2 cells were seeded in a 96-well microplate with $9 \times 10^{4}$ cell/well and $0.1 \mathrm{~mL}$ of growth medium/well for $24 \mathrm{~h}$, respectively. After that, the growth medium was removed and the wells were washed with the PBS buffer 
(pH 7.4, $10 \mathrm{mmol} / \mathrm{L})$. The cells were then incubated with CS(l)-SeNPs, CS(h)-SeNPs, and $\mathrm{H}_{2} \mathrm{SeO}_{3}$, respectively. The Se concentrations varied between 50 and $500 \mu \mathrm{mol} / \mathrm{L}$. The control groups were treated without the above $\mathrm{Se}$ samples. The incubation was performed for another $24 \mathrm{~h}$. At the end of the incubation, the cells were rinsed three times with a cold PBS buffer $\left(4{ }^{\circ} \mathrm{C}\right)$ in order to remove the excess nanoparticles around the cells. Finally, these cells were incubated with DCFH-DA at a final concentration of $20 \mu \mathrm{m}$ at $37^{\circ} \mathrm{C}$ for $60 \mathrm{~min}$. The level of the intracellular ROS was examined by detecting the fluorescence intensity conducted with a Thermo Scientific Varioskan ${ }^{\circledR}$ Flash Multimode Reader (with the excitation and emission wavelength set at 488 and $525 \mathrm{~nm}$, respectively).

\section{Animals and treatments}

The Kunming (KM) mice (Strain code: 202, initial weight: $20 \mathrm{~g}$ to $25 \mathrm{~g}$ ) were purchased from Vital River Laboratories Co., Ltd. (Beijing, China). These mice were allowed free access to food and water. All animal procedures were conducted in accordance with the Animal Care and Use Guidelines of the China Council on Animal Care (Regulations on the Administration of Laboratory Animals, 2013 Revision published by the State Council on July $18,2013)$. The protocol complied with the guidelines of China Agriculture University for the care and use of laboratory animals.

\section{Acute toxicity}

A total of $120 \mathrm{KM}$ mice were randomly divided into 12 groups, with equal numbers of female and male in each group. The $\mathrm{CS}(\mathrm{l})-\mathrm{SeNPs}$ and $\mathrm{H}_{2} \mathrm{SeO}_{3}$ were administered by single intragastric administration with increasing doses (1.43-fold), and the mortalities were recorded within 14 days. The values of LD50 and 95\% confidence were calculated by Trimmed Spearman-Kaber's Method [35].

\section{Transdermal tests of CS-SeNPs}

The transdermal tests were conducted using a vertical Franz diffusion cell system (TP-6, Tianguang Photoelectric Instrument Co., Tianjin, China) equipped with 6 identical diffusion cells. Each cell contained a donor compartment and a receptor compartment filled with $17 \mathrm{~mL}$ normal saline. These two compartments were connected through a circular channel with a cross-sectional area of $3.4 \mathrm{~cm}^{2}$ (Fig. 1). A piece of mouse dorsal skin, free of subcutaneous fat, tissues, blood vessels, and epidermal hairs, was mounted on the channel as a diffusion membrane with the stratum corneum facing the donor compartment. The sample solutions were added in the donor compartment for $6 \mathrm{~h}$, and the substance through the skin was collected with the normal saline stirred at a rate of $600 \mathrm{rpm}$ at $37^{\circ} \mathrm{C}$.

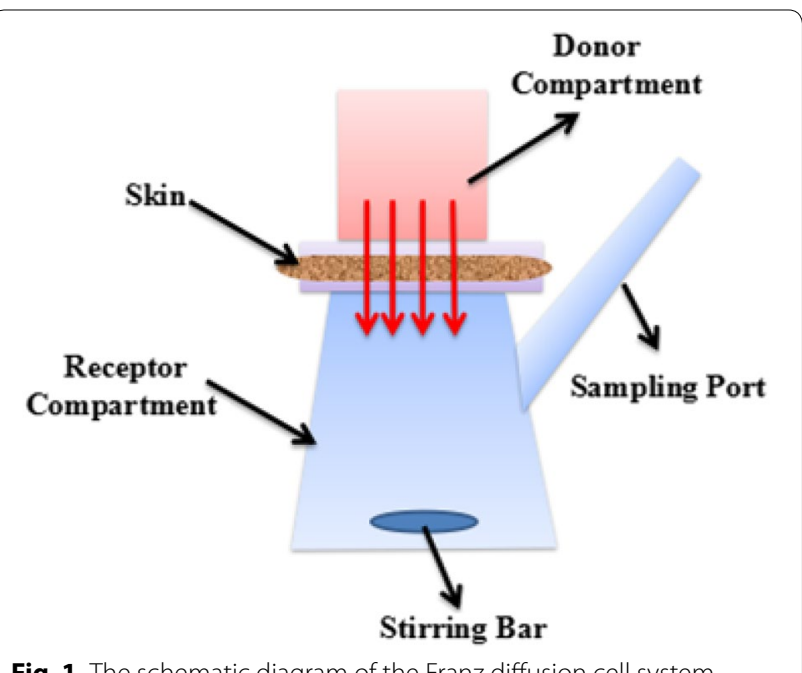

Fig. 1 The schematic diagram of the Franz diffusion cell system

The Se concentration in the donor compartment was kept at $2 \mathrm{mM}$, and the Se through the skin was collected and determined by means of hydride-generation atomic fluorescence spectrometry (AFS-230E, Beijing Haiguang Instrument Co., Beijing, China) as the following procedure noted in literature [36]: the collected solutions were filtered with $0.45 \mu \mathrm{m}$ Millipore filter and then heated with $5 \mathrm{~mL} \mathrm{HClO}_{4} / \mathrm{HNO}_{3}(1 / 3, \mathrm{~V} / \mathrm{V})$ mixture and $3 \mathrm{~mL} \mathrm{HCl}$ to eliminate the organic impurities. After cooling, $5 \mathrm{~mL}$ deionized water, $1 \mathrm{~mL}$ EDTA (1\%), $1 \mathrm{~mL}$ hydroxylamine hydrochloride $(10 \%)$, and $0.2 \mathrm{~mL}$ cresol red $(0.02 \%)$ was added successively into the filtrates. The $\mathrm{pH}$ was adjusted to 1.5 with $\mathrm{HCl}$ or $\mathrm{NH}_{4} \mathrm{OH}$. The solutions were incubated at $60{ }^{\circ} \mathrm{C}$ for $30 \mathrm{~min}$ after adding $1 \mathrm{~mL}$ DAN $(0.1 \%)$, and then $5 \mathrm{~mL}$ cyclohexane was added into the cooled solutions by shaking. After standing for $30 \mathrm{~min}$, the supernatant was collected and then measured by AFS with excitation and emission wavelengths at 376 and $520 \mathrm{~nm}$, respectively.

\section{Bioactivity of CS-SeNPs in the UV-induced skin damage model}

A total of 48 male mice were randomly divided into 6 groups with 8 mice in each group. More details of the procedure were noted in Table 1 . The dorsal skin of the mice was denuded with a wax/rosin mixture $(1: 1, \mathrm{w} / \mathrm{w})$ every 10 days [37]. The drug vehicle was prepared using a standard low-Sun Protection Factor (SPF) cosmetic base formula [38]. The samples were stirred to smooth pastes with the vehicle. The paste was used $30 \mathrm{~min}$ before the UV treatment. The irradiation was made using a UV lamp (TL12rs $40 \mathrm{~W}$ UVB lamp, Philips, Poland) at a dose of $1.0 \mathrm{~kJ} / \mathrm{m}^{2}$ and lasted for 15 days [39]. Then the mice were sacrificed and the dorsal skins were carefully removed 
Table 1 Group, drug dose and UV treatment parameters for the topical tests of the CS-SeNPs

\begin{tabular}{llll}
\hline Group & Se sample & $\begin{array}{l}\text { Dose [mg/kg } \\
\text { body weight }]\end{array}$ & UV radiation \\
\hline UV-induced skin damage & & - \\
1 & - & $/$ & + \\
2 & Drug vehicle & $/$ & + \\
3 & $\mathrm{CS}(\mathrm{I})$-SeNPs (30 days) & 1 & + \\
4 & $\mathrm{CS}(\mathrm{I})$-SeNPs (30 days) & 10 & + \\
5 & $\mathrm{CS}(\mathrm{h})$-SeNPs (30 days) & 1 & + \\
6 & $\mathrm{H}_{2} \mathrm{SeO}_{3}$ & 1 & + \\
\hline
\end{tabular}

and collected to determine LF content and GPx activity. The pathological study of skins was also performed.

\section{Bioactivity of CS-SeNPs in the D-galactose induced mouse aging model}

A total of 48 male mice were randomly divided into 6 groups with 8 mice in each group. More details of the procedure were noted in Table 2. Along with the oral supplementation of the tested samples, a dose of $200 \mathrm{mg} /$ kg D-galactose (drug/body weight) per day was intraperitoneally injected for 4 weeks. The normal saline was used as the blank. Then the mice were sacrificed and the livers and kidneys were immediately collected to determine the LF content and GPx activity.

\section{LF and GPx assessment}

LF content was determined by a modified fluorescence method described in the work of Harvey et al. [40]. A saline solution containing of $10 \%(\mathrm{w} / \mathrm{w})$ skin or viscera was freshly homogenized in an ice-water bath. After mixing $2 \mathrm{~mL}$ of this homogenate with a $4 \mathrm{~mL}$ of the $\mathrm{CHCl}_{3} /$ $\mathrm{MeOH}(2: 1, \mathrm{v} / \mathrm{v})$ extraction agent, the solution was sonicated for $30 \mathrm{~min}$ and then centrifuged at $5000 \mathrm{rpm}$ for $1 \mathrm{~min}$. The lower chloroform phase in the tube was carefully collected with a syringe for the following measurement. The LF content was determined using the following relationship:

$$
\begin{aligned}
& \text { Lipofuscin content }(\mathrm{mg} / \mathrm{g} \text { tissue }) \\
& \begin{array}{l}
=\frac{\mathrm{I}_{\text {sample }}-\mathrm{I}_{\text {control }}}{\mathrm{I}_{\text {standard }}} \times \mathrm{C}_{\text {standard }}(0.1 \mathrm{mg} / \mathrm{mL}) \\
\quad \times \frac{\mathrm{V}_{\text {extract }}(4 \mathrm{~mL})}{\mathrm{W}_{\text {tissue }}(\mathrm{g})}
\end{array}
\end{aligned}
$$

where $\mathrm{I}_{\text {sample }}$ is $\mathrm{LF}, \mathrm{I}_{\text {control }}$ is the $\mathrm{CHCl}_{3} / \mathrm{MeOH}$ extraction agent, and $\mathrm{I}_{\text {standard }}$ is the calibration against a quinine sulfate solution $\left(1 \mu \mathrm{g} / \mathrm{mL}, 0.1 \mathrm{~mol} / \mathrm{L} \mathrm{H}_{2} \mathrm{SO}_{4}\right)$. The wavelengths of the excitation and emission were 365 and $435 \mathrm{~nm}$, respectively.
Table 2 Group, drug dose, and D-galactose parameters for the topical tests of CS-SeNPs

\begin{tabular}{llll}
\hline Group & Se sample & $\begin{array}{l}\text { Dose }[\mathbf{m g} / \mathbf{k g} \text { body } \\
\text { weight }]\end{array}$ & $\begin{array}{l}\text { D-Galac- } \\
\text { tose }\end{array}$ \\
\hline D-Galactose induced aging & & \\
1 & - & $/$ & - \\
2 & Drug vehicle & $/$ & + \\
3 & $\mathrm{CS}(\mathrm{l})$-SeNPs (30 days) & 1 & + \\
4 & $\mathrm{CS}(\mathrm{l})$-SeNPs (30 days) & 10 & + \\
5 & $\mathrm{CS}(\mathrm{h})-S e N P S(30$ days) & 1 & + \\
6 & $\mathrm{H}_{2} \mathrm{SeO}_{3}$ & 1 & + \\
\hline
\end{tabular}

The GPx activity, expressed as NU/mg protein, was determined using a Total Glutathione Peroxidase Assay Kit according to the manufacturer's protocol (Beyotime Biotechnology, Jiangsu, China). The protein concentrations were determined by means of Bradford dye-binding assay using bovine serum albumin as the standard [41].

Histological measurements and ultrathin sections for SEM The histological tests of dorsal skin from the mice used for the UV-radiation test were performed in accordance with standard laboratory procedures. The biopsy skin samples $(2 \mathrm{~cm} \times 3 \mathrm{~cm})$ were cut into small pieces, fixed in $10 \%$ formalin, and then embedded in paraffin. The samples were sliced into 2 - $\mu$ m-thick sections and then stained with hematoxylin and eosin staining. The observations were performed using an optical microscope controlled with TSView software in version 7.0 (Chong Qing Optical and Electrical Instrument Co., Ltd. Chongqing, China).

KM mice were deprived of food for over $24 \mathrm{~h}$ and were orally administered the CS-SeNPs solution and the CSSeNPs lotion at a dosage of $25 \mathrm{mg} \mathrm{Se} / \mathrm{kg}$ mice on the skin. After $6 \mathrm{~h}$ of exposure, biopsy samples from the small intestines and dorsal skin were immediately obtained for SEM observation. The ultrathin sections were made as following [42]. The small intestines and dorsal skin were quickly sliced into small pieces $(1 \mathrm{~mm} \times 1 \mathrm{~mm})$, and then washed and fixed with $2.5 \%$ glutaraldehyde in PBS buffer ( $\mathrm{pH} 7.4,10 \mathrm{mmol} / \mathrm{L}$ ). The fixed samples were dehydrated with graded ethanol solutions $(70,80,90$, and $100 \%$, $\mathrm{v} / \mathrm{v}$, ethanol/water) and $50 \%$ acetone (v/v, acetone/ethanol), and then dehydrated twice with pure acetone. Each dehydration process lasted for $15 \mathrm{~min}$. These samples were embedded in graded QUETOL 651 resin solutions $(1 / 3,1 / 1,3 / 1, \mathrm{v} / \mathrm{v}$, resin/acetone) and pure resin (with DMP-30) overnight. After standing for $24 \mathrm{~h}$ at $60{ }^{\circ} \mathrm{C}$, the samples were cut into ultrathin pieces of about $70-\mathrm{nm}$ thickness with a Leica EMUC6 ultramicrotome and then placed on a carbon-coated copper grid. Digital images 
were acquired with a Zeiss Merlin Scanning Electric Microscope (Germany) and elementary analysis was conducted with a Horiba INCA 450 energy dispersive $\mathrm{x}$-ray analysis spectroscopy.

\section{Statistical analysis}

All experiments were conducted in triplicate and expressed as mean \pm SD. Statistical analysis was performed using Origin 8.5 and SPSS 16.0. The comparison was performed with $\chi^{2}$ or one-way ANOVA, followed by Dunnett's multiple comparison tests. Statistically significant differences between groups were defined as $p<0.05$.

\section{Results and discussion}

\section{Characterization of chitosan stabilized selenium nanoparticles}

The preparation of the CS-SeNPs was performed according to our previous work [21]. The CS(l)-SeNPs (Fig. 2a) formed uniform small sphere particles with a size of about $50 \mathrm{~nm}$, while the CS(h)-SeNPs (Fig. 2b) formed loose and irregular aggregates with an average size of more than $350 \mathrm{~nm}$ caused by the bridging effect of the long macromolecular chains during the initial stage of their formation. In 30 days, via a "bottom-up" growth or "top-down" shrinkage process, respectively, both the size of the CS(l)-SeNPs and CS(h)-SeNPs tended to be about $103 \mathrm{~nm}$. As depicted in the previous work, the cores of $\mathrm{CS}(\mathrm{h})$-SeNPs were more scattered than those of CS(l)SeNPs. The zeta potential of CS(l)-SeNPs decreased from $49.5 \pm 0.9$ to $33.5 \pm 1.0 \mathrm{mv}$ and that of CS(h)-SeNPs changed from $65.9 \pm 0.1$ to $44.8 \pm 0.6 \mathrm{mv}$. The comparison of the zeta potential values indicated that the loose microstructure of CS(h)-SeNPs was caused by its relatively high intermolecular electrostatic repulsion and

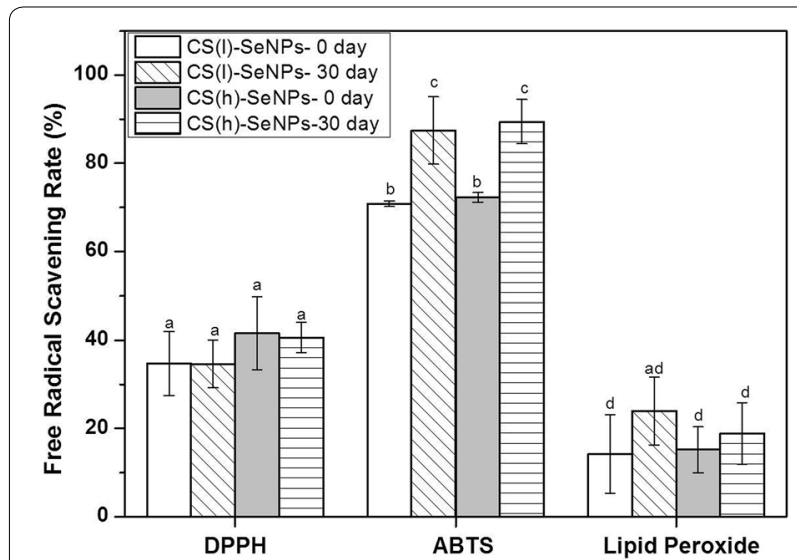

Fig. 3 Comparison of the antioxdiant capacities of CS-SeNPs in DPPH, ABTS and lipid peroxidation systems. The different letter markers denote the significant mean difference at $p<0.05$

bridging effects. It was believed that such a loose microstructure of $\mathrm{CS}(\mathrm{h})$-SeNPs led to its relatively higher Se release rate compared with that of CS(1)-SeNPs [21].

\section{Antioxidant capacities of CS-SeNPs in vitro}

The antioxidant capacities in vitro of the CS-SeNPs were investigated using the assays reported in literature, most of them can be classified into two types [44]: assays based on electron transfer (ET-based) such as DPPH and ABTS, and assays based on hydrogen atom transfer (HAT-based) reactions such as lipid peroxidation, depending upon the chemical reactions involved. Among them, DPPH and lipid peroxidation were carried out in hydrophobic media, while ABTS was in hydrophilic media. In order to understand the multifaceted aspects of the CS-SeNPs,
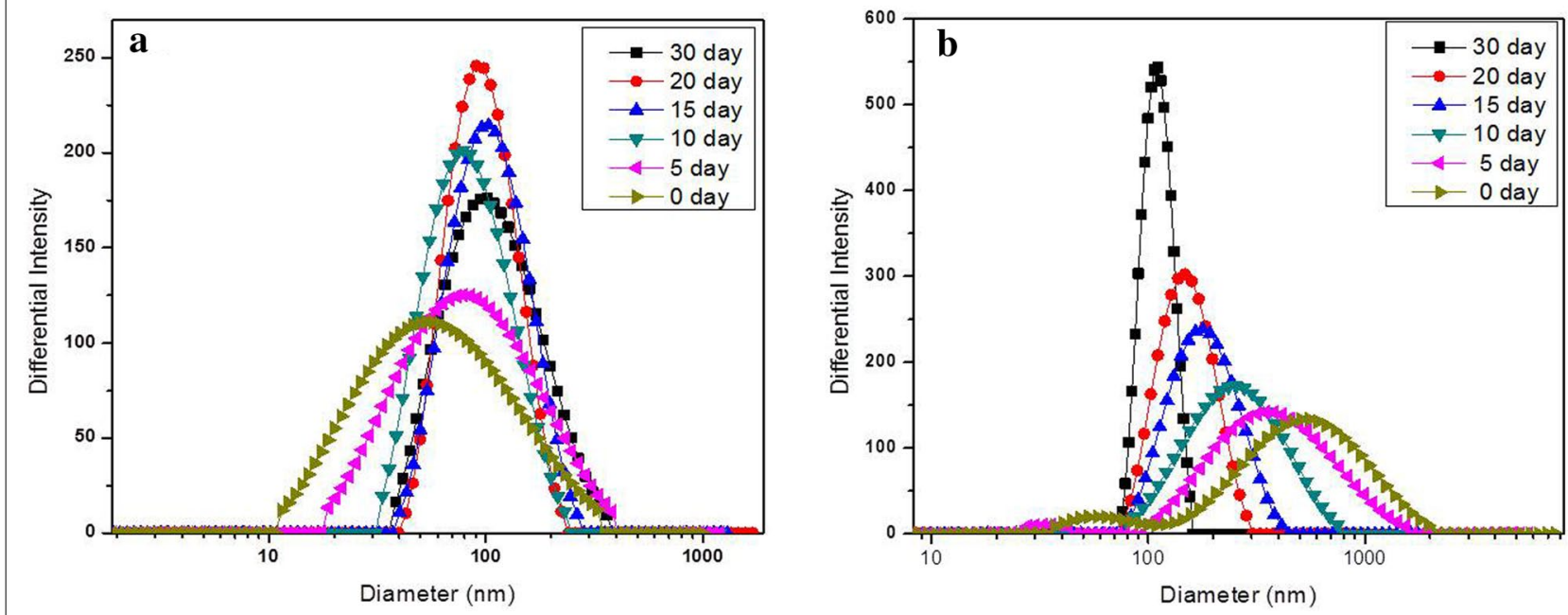

Fig. 2 The size parameters of CS-NPS. (a) CS(I)-SeNPs; (b) CS(h)-SeNPS 
the above assays were all used and results were compared in Fig. 3.

It was observed that the values of RSC\% in ABTS were higher than those in DPPH and lipid peroxidation. This feature was due to the effect of the high water solubility of the nanoparticles, which led to the separation of the Se nanoparticle-rich water phase from the free radicalrich lipid phase, and thus reduced the ability of $\mathrm{Se}^{0}$ to capture the free radicals. The somewhat higher values of RSC\% in DPPH than in lipid peroxidation indicated that the nanoparticles were more likely to ET-based reaction rather than HAT-based reaction. This behavior was different from that of some organic antioxidants such as rutin, which could react quickly with lipid peroxyl radicals but not nitrogen radicals [42]. The discussion about the difference between Se and organic antioxidants was not discussed because it was beyond the scope of this work.

Figure 3 also revealed the storage effect on the antioxidant capacities of CS-SeNPs. It was observed that the $\mathrm{RSC} \%$ of the nanoparticles was enhanced by approximately $25 \%$ after a treatment of 30 days storage in ABTS assay. Such enhancement was normally caused by the protection of the stabilized CS shell on the antioxidant activity of Se during storage. This effect was not significant in DPPH and lipid peroxidation $(p<0.05)$, which was probably due to the low level of RSC\% concealing the difference between these assays. Anyway, the use of the

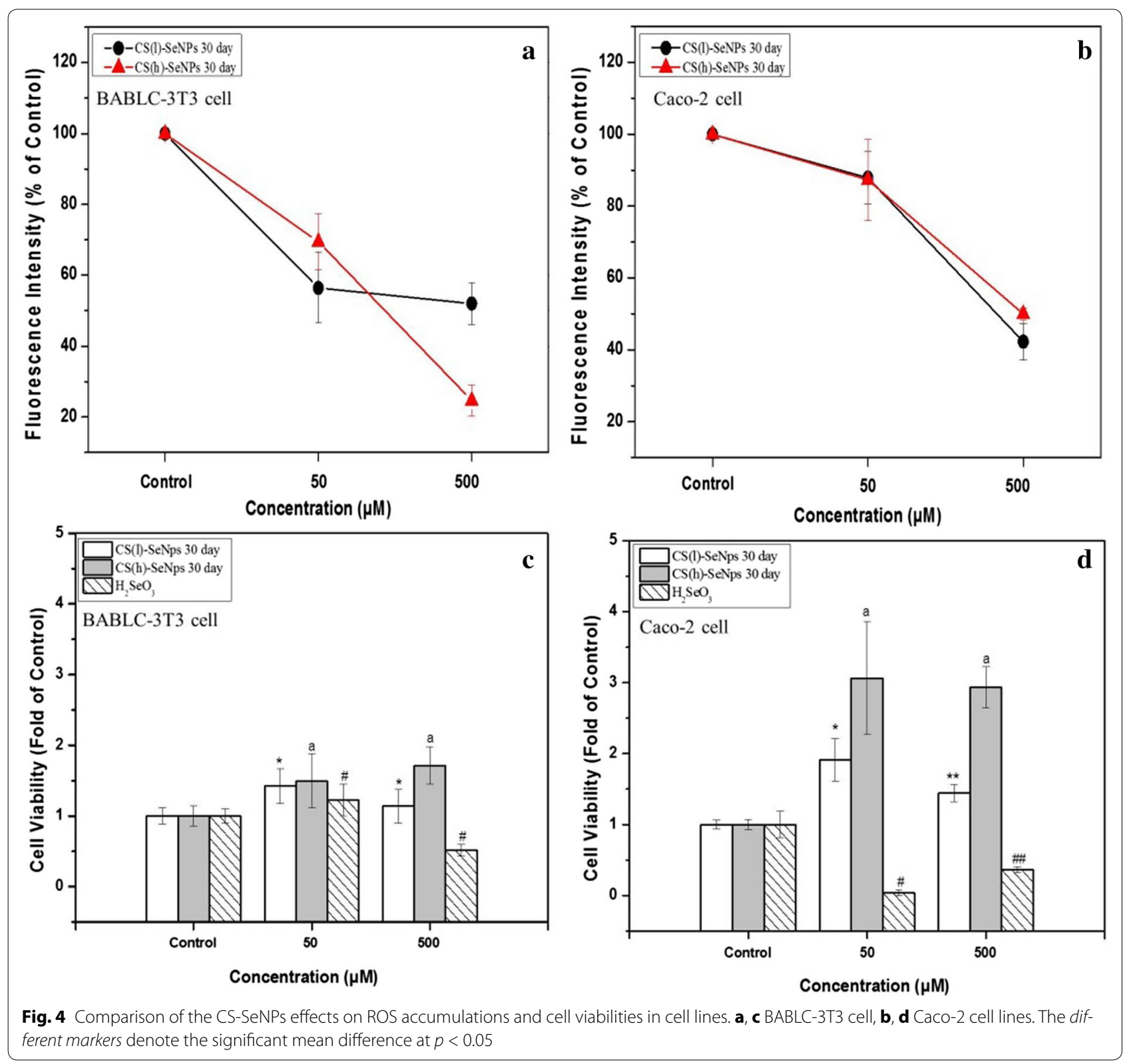


stabilized nanoparticles was the best choice for the following experiments. No effect of CS molecular weight was observed in all tests in vitro. Although the CS molecular weight could affect the Se release rate via the modification of the nano-carrier microstructure, the minor difference of the released Se quantities was not serious enough to disturb the antioxidant capacities in the present experimental conditions.

\section{ROS inhibition effects and cytotoxicity of CS-SeNPs in vitro}

An appropriate antioxidant capacity of Se nanoparticles can be used to inhibit ROS accumulation in cell, while an excessive one will result in cytotoxicity. Since the skin and digestive tract were targeted in this work, the BABLC 3T3 (a) and Caco-2 (b) cell lines were used as skin [30] and intestinal cell [45] models to test ROS inhibition effects and cytotoxicity of CS-SeNPs (Fig. 4).

Both CS(l)-SeNPs and CS(h)-SeNPs could inhibit ROS accumulation in BABLC-3T3 cell lines in a dose-dependent manner, but a larger rate of divergence existed, and an abnormal strong inhibition effect was observed with a high dose $(500 \mu \mathrm{M})$ of CS(h)-SeNPs. While in Caco-2 cell lines, the inhibitory effects of both nanoparticles increased at almost the same rate as the drug dose.

The Se nanoparticles were cytotoxic. Zheng et al. have studied the properties of a grey Se stabilized with polyethylene glycol, PEG-SeNPs, in HepG2 cell lines [43]. They found that the PEG and Se had a synergetic effect on cell apoptosis via the induction of mitochondrial dysfunction. However, compared with $\mathrm{H}_{2} \mathrm{SeO}_{3}$, it was obviously observed that CS nano-systems could effectively reduce the selenium cytotoxicity in BABLC-3T3 (Fig. 4c) and Caco-2 (Fig. 4d) cell lines, respectively. The values of the cell viability of $\mathrm{CS}(\mathrm{h})$-SeNPs were generally higher than those of CS(l)-SeNPs. Nevertheless a dose-dependent manner could be observed for CS(l)-SeNPs, but not for CS(h)-SeNPs. The properties of the former needs to be further studied, where the relationship between the physicochemical properties of the nanoparticles and biochemical properties of the cells should be considered. In this work, the CS(l)-SeNPs were preferentially used in the subsequent tests.

\section{Penetration tests of CS-SeNPs}

The bio-activities of nanoparticles are related to their penetration ability. This ability can be affected by the nanoparticle surface coatings and also the biochemical characteristics of target organelle or tissue [46]. Since the skin contact and intestinal intake were concerned in this work, the dorsal skin and intestinal tissues of mice were used as models to test the transdermal capacities of the CS-SeNPs, respectively.

Figure 5 exhibited SEM observation of Se nanoparticles in the dorsal skin and intestinal tissues of mice (a) and compared the transdermal kinetic data of CS(l)-SeNPs, $\mathrm{CS}(\mathrm{h})$-SeNPs, and $\mathrm{H}_{2} \mathrm{SeO}_{3}$ (b) in the skin. The kinetic analysis of the intestinal system was not performed, because the Se quantity before the penetration process could be affected by the portion of Se released in intestine tract [21], and the state of Se accumulation on the surface of intestine wall should be also considered. As shown in Fig. 5a, it was observed that Se nanoparticles could easily penetrate cell membrane and stay near the rough endoplasmic reticulum and mitochondria. In contrast, recent reports have shown the interactions of $\mathrm{Se}$ nanoparticles with mitochondria [47] and lysosome [48]. Obviously, it appears that the distribution of nanoparticles in cell was quite broad.
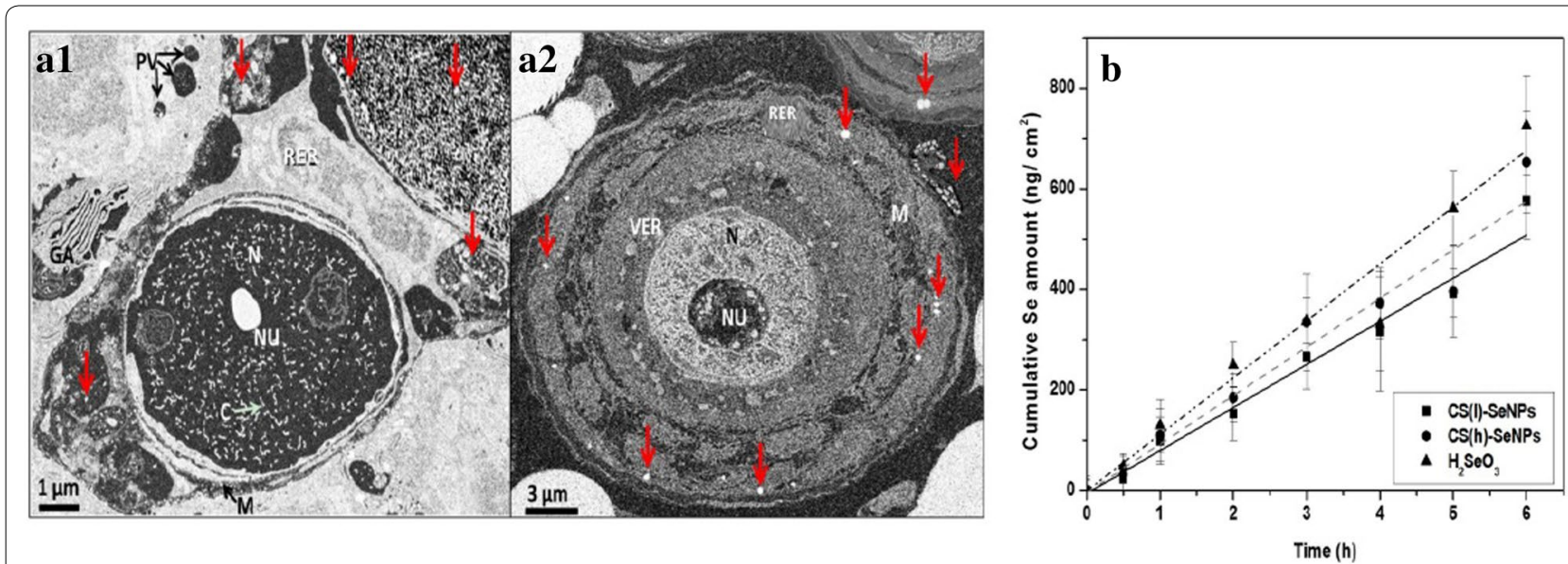

Fig. 5 SEM observation and transdermal tests of CS-SeNPs in mice tissue. a Small intestine (a1) and skin (a2). N nucleus, NU nucleolus, C chromatin, $R E R$ rough endoplasmic reticulum, $M$ mitochondria, $V E R$ vacuolization of the endoplasmic reticulum, GA Golgi apparatus, and $P V$ pinocytic vesicle. The Se particles in the cell are marked with red arrows. $\mathbf{b}$ Comparison of the transdermal kinetics of the CS-SeNP and $\mathrm{H}_{2} \mathrm{SeO}_{3}$ 
Passive diffusion was denoted as the principle penetration mode of $\mathrm{SeO}_{3}{ }^{2-}$ [49] while endocytosis often happened in nanosystems [14]. Nevertheless, the transdermal Se amount of CS(l)-SeNPs, CS(h)-SeNPs, and $\mathrm{H}_{2} \mathrm{SeO}_{3}$ was very close and approximately showed a linear relationship with time. The rate values were at about $85.7 \pm 5.5,95.7 \pm 3.5$ and $112.9 \pm 0.8 \mathrm{ng} / \mathrm{cm}^{2} \mathrm{~h}$, respectively (Fig. 5b), indicating that Se delivery efficiency of the CS-SeNPs was considerable to that of selenite ion diffusion.

\section{Antioxidant capacities of CS-SeNPs in vivo}

The investigations of the CS-SeNPs antioxidant capacities in vivo were conducted using the KM mouse skin (Fig. 6) or viscera (Fig. 7) treated with UV-radiation or D-galactose, respectively.

\section{UV-radiation system}

Figure 6 exhibited the optical micrographs of the mouse skin (a, b, c, and d: skin surfaces; e, f, g, and h: skin crosssections) and compared the GPx (i) activity and LF level

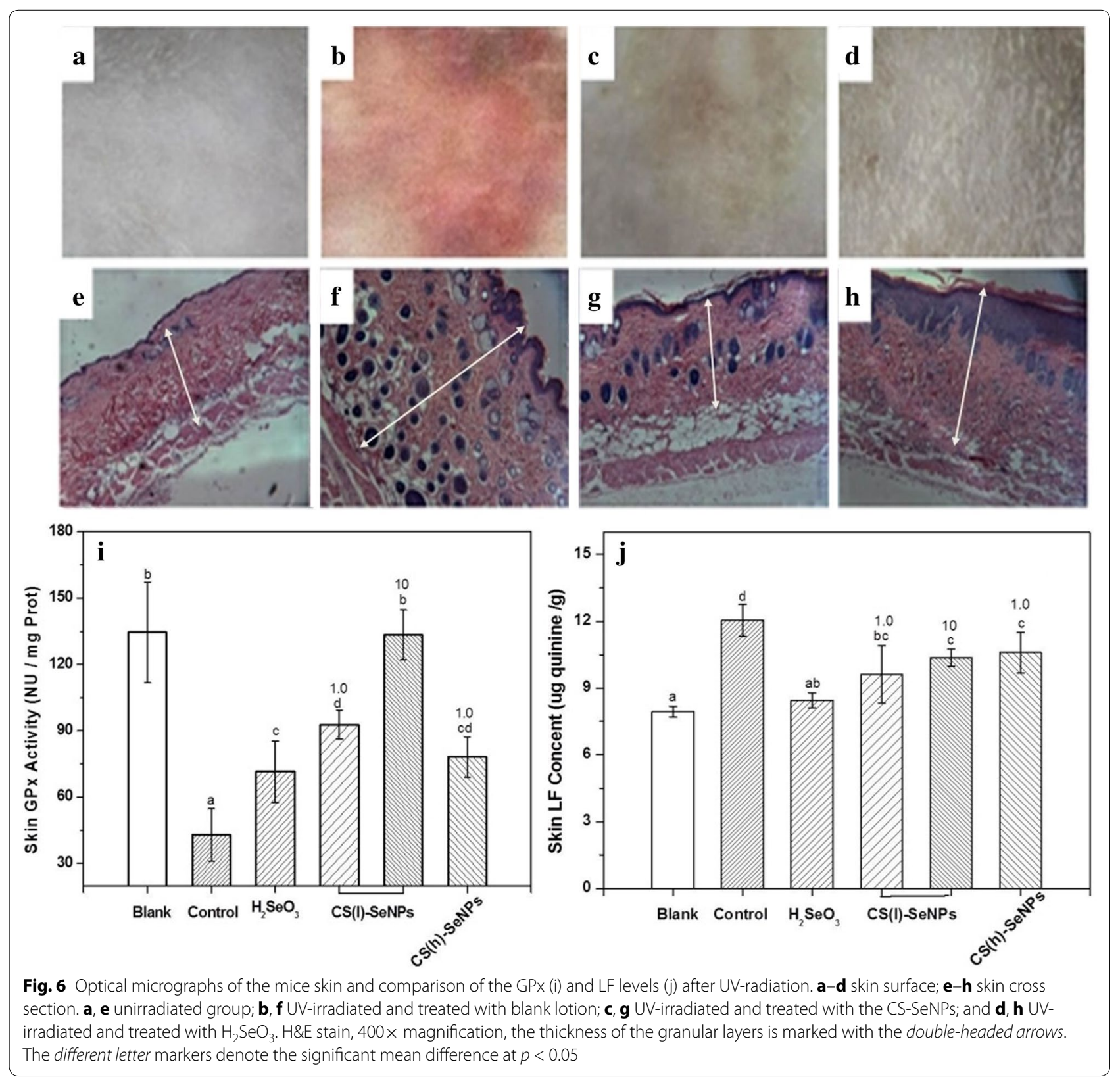


(j) after UV-radiation. The surface (Fig. 6a) and crosssection (Fig. 6e) of the unirradiated skin were used as the blank, which had relatively high GPx activity and low LF. After a 15-day UV-radiation treatment, a palpable pathological pigmentation could be observed on the surface (Fig. 6b), and a number of dark granules appeared in the cross section (Fig. 6f). Meanwhile, the level of GPx activity was sharply reduced and LF increased. This irradiated group, without any antioxidant treatment, was used as the control. Under the same dose of UV radiation, the level of the pathological pigmentation and the thickness of the granular layer were greatly reduced for the skin treated with CS-SeNPs (Fig. 6c, g) or $\mathrm{H}_{2} \mathrm{SeO}_{3}$ (Fig. 6d, h), respectively. For these two Se samples, the former was better to protect GPx activity than the latter in respect to the same Se dose $(1 \mathrm{mg} / \mathrm{kg}$, drug/body weight). As for the two types of CS-SeNPs, CS(l)-SeNPs was better than $\mathrm{CS}(\mathrm{h})$-SeNPs, and the concerned effect could be improved in a dose-dependent manner. The LF level could be reduced by CS-SeNPs. However, no significant dose-dependence was observed in the present dose range.

\section{D-galactose system}

Figure 7 compares the effects of CS-SeNPs on GPx activity and LF level in KM mouse livers and kidneys treated with D-galactose, respectively. In both viscera models, D-galactose increased the LF level and reduced GPx
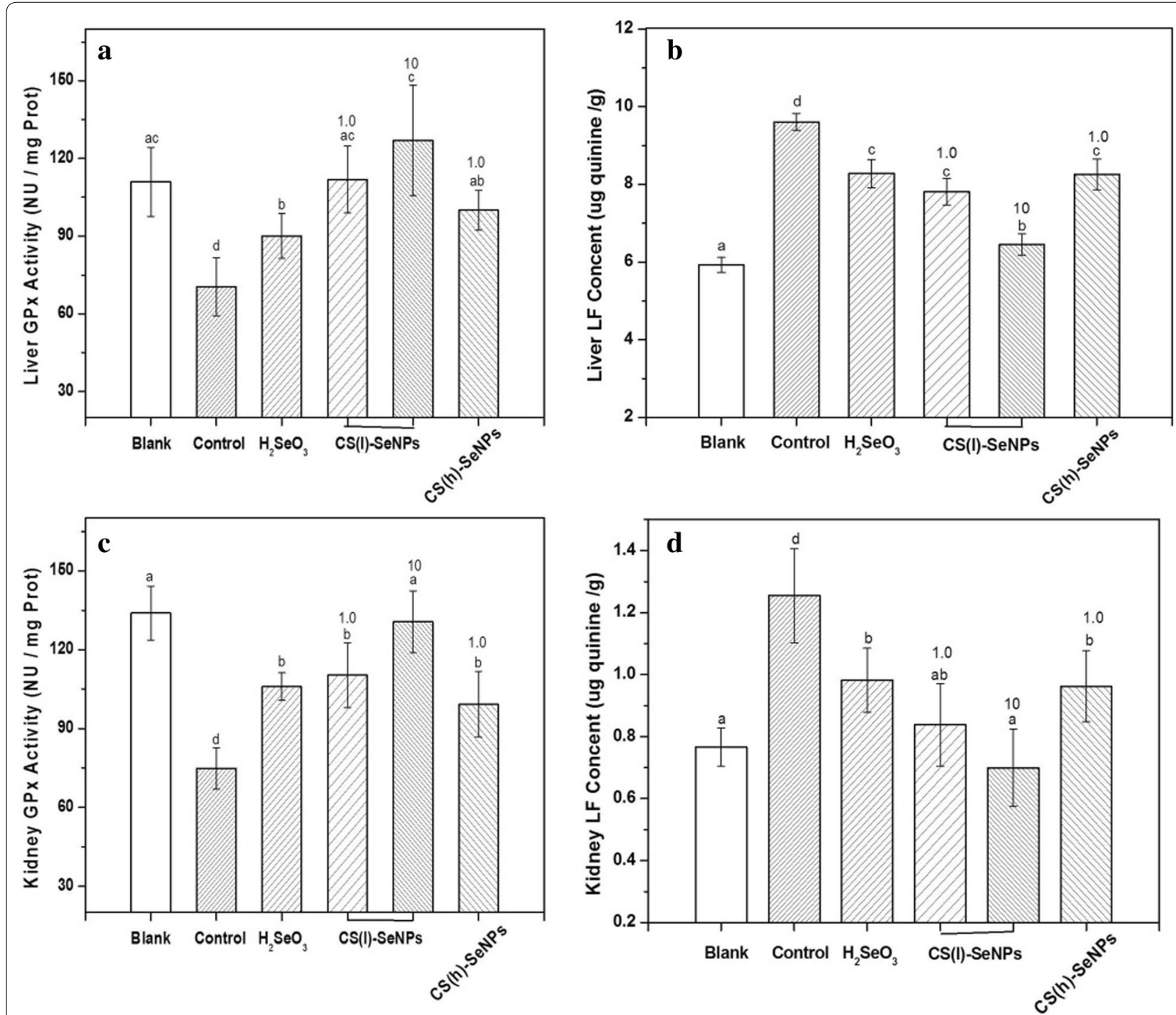

Fig. 7 Comparison of the bio-activities of the orally administered CS-SeNPs on the livers or kidneys of the mice. $\mathbf{a}$, $\mathbf{b}$ GPx, LF levels in the livers; $\mathbf{c}, \mathbf{d}$ GPx, LF levels in the kidneys. The different letter markers denote the significant mean difference at $p<0.05$ 
Table 3 Acute lethal effect of Se samples by oral administration

\begin{tabular}{|c|c|c|c|}
\hline \multicolumn{2}{|l|}{$\mathrm{H}_{2} \mathrm{SeO}_{3}$} & \multicolumn{2}{|l|}{ CS(I)-SeNPs } \\
\hline $\begin{array}{l}\text { Selenium dose } \\
\text { (mg drug/ } \\
\text { body) }\end{array}$ & $\begin{array}{l}\text { Mouse mortal- } \\
\text { ity (\%) }\end{array}$ & $\begin{array}{l}\text { Selenium dose } \\
\text { (mg drug/ } \\
\text { body) }\end{array}$ & $\begin{array}{l}\text { Mouse mortality } \\
\text { (\%) }\end{array}$ \\
\hline 7.1 & 0 & 74.1 & 0 \\
\hline 10.7 & 10 & 111.1 & 10 \\
\hline 16.0 & 40 & 166.7 & 10 \\
\hline 24.0 & 60 & 250.0 & 50 \\
\hline 36.0 & 90 & 375.0 & 90 \\
\hline
\end{tabular}

activities. Well, the presence of the Se substance could weaken the effects of D-galactose. Similar results were reported elsewhere [50]. Among these Se substances, $\mathrm{CS}(\mathrm{l})$-SeNPs was better than both $\mathrm{H}_{2} \mathrm{SeO}_{3}$ and $\mathrm{CS}(\mathrm{h})$ SeNPs to protect the GPx activities (Fig. 7a, c) and reduce LF accumulation (Fig. 7b, d) with the same Se dose (1 mg/ $\mathrm{kg}$, drug/body weight). The effects of the CS(l)-SeNPs could also be improved in a dose-dependent manner.

The dosages of the drugs were limited by their toxicity. The toxic doses of $\mathrm{H}_{2} \mathrm{SeO}_{3}$ and $\mathrm{CS}(\mathrm{l})$-SeNPs were compared in Table 3. According to literature [51], the moderately toxic dose and highly toxic doses were categorized as $50-500$ and $5-50 \mathrm{mg} / \mathrm{kg}$ (drug/body weight), respectively. The $\mathrm{LD} 50$ of $\mathrm{H}_{2} \mathrm{SeO}_{3}$ was $22.0 \mathrm{mg} / \mathrm{kg}$ with 95\% confidence from 15.9 to 30.4 and was highly toxic while the CS(l)-SeNPs, with LD50 of $258.2 \mathrm{mg} / \mathrm{kg}$ with 95\% confidence between 193.9 and 343.9, belonged to a moderately toxic substance. A similar result was reported by Wang et al. in which the LD50 of Se nanoparticle was at the level of $113.0 \mathrm{mg} / \mathrm{kg}$ with $95 \%$ confidence being 89.9-141.9 [6].

\section{Conclusions}

In conclusion, the antioxidant abilities of the Se nanoparticles stabilized with different CS, i.e. CS(l)-SeNPs and CS(h)-SeNPs, could be enhanced by a 30-day storage process. The transdermal Se delivery efficiency of these CS-SeNPs was equivalent to that of selenite. The good abilities to penetrate cell or tissue have made these nanoparticles to be able to effectively inhibit ROS accumulation, reduce Se cytotoxicity, protect GPx activity and prevent LF accumulation, in vitro or in vivo. The $\mathrm{UV}$-radiation or D-galactose tests indicated that the antioxidant capacities of CS-SeNPs were more evident in viscera than in skin of mice. However, regarding the aspect of dose effect control, CS(l)-SeNPs was found more efficient than $\mathrm{CS}(\mathrm{h})$-SeNPs. From a more prospective point of view, we believe that further studies will be needed to explore the metabolic fate and long-term fate, stability and potential transformation of the chitosan selenium nanoparticles in vivo.

\begin{abstract}
Abbreviations
Se: selenium; $\mathrm{Se}^{0}$ : the element Se with zero oxidation state; SeNPs: $\mathrm{Se}^{0}$ nanoparticles; CS: chitosan; Mws: molecular weigthts; CS-SeNPs: selenium nanoparticles stabilized with chitosan; CS(I)-SeNPs: selenium nanoparticles with the low molecular weight chitosan; CS(h)-SeNPs: selenium nanoparticles with the high molecular weight chitosan; ROS: reactive oxygen species; GPx: glutathione peroxidase; LF: lipofusin; $\mathrm{H}_{2} \mathrm{SeO}_{3}$ : the seleninic acid; ABTS: 2, 2'-Azino-bis (3-ethylbenzothiazoline-6-sulfonic acid; DPPH: 2, 2-diphenyl1-picrylhydrazyl; DAN: 2, 3-diaminonaphthalene; DCFH-DA: 2',7'-dichlorofluorescein diacetate; DMP-30: 2,4,6-Tris(dimethylaminomethyl) phenol; DMEM: Dulbecco's modified Eagle medium; NEAA: MEM nonessential amino acid solution; DMSO: dimethyl sulfoxide; PBS: potassium phosphate; CS3: chitosan with a molecular weight of less than $3 \mathrm{kDa}$; CS200: chitosan with a molecular weight of less than $200 \mathrm{kDa} ; \mathrm{K}_{2} \mathrm{~S}_{2} \mathrm{O}_{8}$ : potassium persulfate; TCA: trichloroacetic acid; TBA: 2-thiobarbituric acid; STEM: scanning transmission electron microscopy; RSC\%: the radicals scavenging activity; MDA: malondialdehyde; MTT: 3-(4, 5-dimethylthiazol-2-yl)-2, 5-diphenyltetrazolium bromide; AFS: hydride-generation atomic fluorescence spectrometry; ET-based: assays based on electron transfer; HAT-based: assays based on hydrogen atom transfer.
\end{abstract}

\section{Authors' contributions}

$X J L, G H Z$, SS, and FZR coordinated the experiments, and provided important advice for each designed the study. CYZ performed the nanoparticles preparing and transdermal tests, XNZ performed the in vitro antioxidant activity assays and the cell experiments, and they completed the animal texts together. All authors contributed to the interpretation of data, the preparation of the paper and approval of the final version. All authors read and approved the final manuscript.

\section{Author details}

${ }^{1}$ Beijing Advanced Innovation Center for Food Nutrition and Human Health, Beijing Laboratory for Food Quality and Safety, Beijing Dairy Industry Innovation Team, College of Food Science \& Nutritional Engineering, China Agricultural University, Beijing 100083, China. ${ }^{2}$ Group of Environmental Physical Chemistry, F.-A. Forel Institute, University of Geneva, Geneva, Switzerland.

\section{Acknowledgements}

We would like to acknowledge Professors Yan and Wei (Beijing National Center for Microscopy, Department of Chemistry, Tsinghua University) for their technical advice. We would also like to thank Professor Jia at the Center for Biological Imaging (CBI), Institute of Biophysics, Chinese Academy of Science for her help in making ultrathin section samples.

\section{Competing interests}

The authors declare they have no competing financial interest.

\section{Availability of data and material}

All data generated or analyzed during this study are included in this published article and our previous work: http://dx.doi.org/10.1016/j.carbpol.2015.07.065.

\section{Ethical approval}

All animal experiments were in accordance with the Animal Care and Use Guidelines of the China Council on Animal Care (Regulations on the Administration of Laboratory Animals, 2013 Revision published by the State Council on July 18, 2013).

\section{Funding}

The study was supported by the National Key Research and Development Program (No. 2016YFD0400804) and Beijing Dairy Industry Innovation Team.

Received: 27 October 2016 Accepted: 26 December 2016

Published online: 05 January 2017 


\section{References}

1. Tapiero $\mathrm{H}$, Townsend DM, Tew KD. The antioxidant role of selenium and seleno-compounds. Biomed Pharmacother. 2003;57:134-44.

2. Liu W, Zheng WJ, Zhang YB, Cao WQ, Chen TF. Selenium nanoparticles as a carrier of 5-fluorouracil to achieve anticancer synergism. ACS Nano. 2012;6:6578-91.

3. McKenzie RC. Selenium, ultraviolet radiation and the skin. Clin Exp Dermatol. 2000;25:631-6.

4. Qin S, et al. Effects of selenium-chitosan on blood selenium concentration, antioxidation status, and cellular and humoral immunity in mice. Biol Trace Elem Res. 2015;165:145-52.

5. Wang WF, et al. Dietary selenium requirement and its toxicity in juvenile abalone Haliotis discus hannai Ino. Aquaculture. 2012;330:42-6.

6. Wang H, Zhang J, Yu H. Elemental selenium at nano size possesses lowe toxicity without compromising the fundamental effect on selenoenzymes: comparison with selenomethionine in mice. Free Radic Biol Med. 2007:42:1524-33.

7. Torres SK, et al. Biosynthesis of selenium nanoparticles by Pantoea agglomerans and their antioxidant activity. J Nanopart Res. 2012;14:1-9.

8. Zhang JS, Wang HL, Yan XX, Zhang LD. Comparison of short-term toxicity between Nano-Se and selenite in mice. Life Sci. 2005;10:1099-109.

9. Chen HY, Shin DW, Nam JG, Kwon KW, Yoo JB. Selenium nanowires and nanotubes synthesized via a facile template-free solution method. Mater Res Bull. 2010:45:699-704

10. Rai M, Yadav A, Gade A. Silver nanoparticles as a new generation of antimicrobials. Biotechnol Adv. 2009;27:76-83.

11. Daniel MC, Astruc D. Gold nanoparticles: assembly, supramolecular chemistry, quantum-size-related properties, and applications toward biology, catalysis, and nanotechnology. Chem Rev. 2004;104:293-346.

12. Schubert D, Dargusch R, Raitano J, Chan SW. Cerium and yttrium oxide nanoparticles are neuroprotective. Biochem Biophys Res Commun. 2006;342:86-91

13. Kim J, et al. Effects of a potent antioxidant, platinum nanoparticle, on the lifespan of Caenorhabditis elegans. Mech Aging Dev. 2008;129:322-31.

14. Peters RJB, et al. Nanomaterials for products and application in agriculture, feed and food. Trends Food Sci Technol. 2016:54:155-64.

15. Kaur G, labal M, Bakshi MS. Biomineralization of fine selenium crystalline rods and amorphous spheres. J Phys Chem C. 2009;113:13670-6.

16. Zhang YF, Wang JG, Zhang LN. Creation of highly stable selenium nanoparticles capped with hyperbranched polysaccharide in water. Langmuir. 2010;26:17617-23.

17. Wu SS, Sun K, Wang X, Wang DX, Wan XC, Zhang JS. Protonation of epigallocatechin-3-gallate (EGCG) results in massive aggregation and reduced oral bioavailability of EGCG-dispersed selenium nanoparticles. J Arg Food Chem. 2013;61:7268-75

18. Estevez H, Garcia-Lidon JC, Luque-Garcia JL, Cmara C. Effects of chitosanstabilized selenium nanoparticles on cell proliferation, apoptosis and cell cycle pattern in HepG2 cells: comparison with other selenospecies. Colloid Surf B. 2014:122:184-93.

19. Anal AK, Stevens WF, Remuñán-López C. Ionotropic cross-linked chitosan microspheres for controlled release of ampicillin. Int J Pharm. 2006;312:166-73

20. Roncal T, Oviedo A, Armentia IL, Fernández DL, Villarán MC. High yield production of monomer-free chitosan oligosaccharides by pepsin catalyzed hydrolysis of a high deacetylation degree chitosan. Carbohyd Res. 2007;342:2750-6.

21. Zhang CY, Zhai XN, Zhao GH, Ren FZ, Leng XJ. Synthesis, characterization, and controlled release of selenium nanoparticles stabilized by chitosan of different molecular weights. Carbohyd Polym. 2015;134:158-66.

22. Blagosklonny MV. Aging: Ros or tor. Cell Cycle. 2008;7:3344-54.

23. Brunk UT, Terman A. Lipofuscin: mechanisms of age-related accumulation and influence on cell function. Free Radic Biol Med. 2002;33:611-9.

24. Family F, Mazzitello Kl, Arizmendi CM, Grossniklaus HE. Dynamic scaling of lipofuscin deposition in aging cells. J Stat Phys. 2011;144:332-43.

25. Höhn A, König J, Grune T. Protein oxidation in aging and the removal of oxidized proteins. J Proteom. 2013:92:132-59.

26. Terman A, Brunk ULFT. Lipofuscin: mechanisms of formation and increase with age. Apmis. 1998;106:265-76.
27. Thorling EB, Overvad K, Bjerring P. Oral selenium inhibits skin reactions to UV light in hairless mice. Acta Pathologica Microbiologica Scandinavica Series A: Pathol. 1983:91:81-4.

28. Overvad K, Thorling EB, Bjerring P, Rbbesen P. Selenium inhibits UV-lightinduced skin carcinogenesis in hairless mice. Cancer Lett. 1985;27:163-70.

29. Burke KE, Combs-Jr GF, Gross EG, Bhuyan KC, Abu-Lideh H. The effects of topical and oral L-selenomethionine on pigmentation and skin cancer induced by ultraviolet irradiation. Nutr Cancer. 1992;2:123-37.

30. Lynch AM, Wilcox P. Review of the performance of the $3 T 3 \mathrm{NRU}$ in vitro phototoxicity assay in the pharmaceutical industry. Exp Toxicol Pathol. 2011;63:209-14.

31. Xu BJ, Chang SKC. A comparative study on phenolic profiles and antioxidant activities of legumes as affected by extraction solvents. J Food Sci. 2007;72:S159-66.

32. Re R, Pellegrini N, Proteggente A, Pannala A, Yang M, Rice-Evans C. Antioxidant activity applying an improved ABTS radical cation decolorization assay. Free Radic Biol Med. 1999:26:1231-7.

33. Tsuda T, et al. Antioxidative activity of the anthocyanin pigments cyanidin 3-O-. B-D-glucoside and cyaniding. J Agric Food Chem. 1994:42:2407-10.

34. Wolfe KL, Hai LR. Cellular antioxidant activity (CAA) assay for assessing antioxidants, foods, and dietary supplements. J Agric Food Chem. 2007;55:8896-907.

35. Hamilton MA, Russo RC, Thurston RV. Trimmed Spearman-Karber method for estimating median lethal concentrations in toxicity bioassays. Environ Sci Technol. 1977;11:714-9.

36. Olson OE, Palmer IS, Cary EE. Modification of the official fluorometric method for selenium in plants. J Am Heart Assoc. 1975;58:117-21.

37. Müller-Röver $\mathrm{S}$, et al. A comprehensive guide for the accurate classification of murine hair follicles in distinct hair cycle stages. J Invest Dermatol. 2001:117:3-15.

38. Zhao T. Hygienic standard for cosmetics health. Beijing; 2007

39. Pence BC, Delver E, Dunn DM. Effects of dietary selenium on UVBinduced skin carcinogenesis and epidermal antioxidant status. J Invest Dermatol. 1994:102:759-61.

40. Harvey H, Ju SJ, Son S, Feinberg L, Shaw C, Peterson W. The biochemical estimation of age in Euphausiids: laboratory calibration and field comparisons. Deep-Sea Res Part II. 2010;57(7):663-71.

41. Bradford MM. A rapid and sensitive method for the quantitation of microgram quantities of protein utilizing the principle of protein-dye binding. Anal Biochem. 1976;72:248-54.

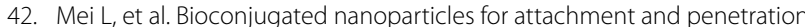
into pathogenic bacteria. Biomaterials. 2013;34:10328-37.

43. Zheng SY, et al. PEG-nanolized ultrasmall selenium nanoparticles overcome drug resistance in hepatocellular carcinoma HepG2 cells through induction of mitochondria dysfunction. Int J Nanomed. 2012;7:3939-49.

44. Huang DJ, Ou BX, Prior R. The chemistry behind antioxidant capacity assays. J Agr Food Chem. 2005;53:1841-56.

45. Sambuy Y, De Angelis I, Ranaldi G, Scarino ML, Stammati A, Zucco F. The Caco-2 cell line as a model of the intestinal barrier: influence of cell and culture-related factors on Caco-2 cell functional characteristics. Cell Biol Toxicol. 2005;21:1-26.

46. Lewinski N, Colvin V, Drezek R. Cytotoxicity of nanoparticles. Small. 2008;4:26-49.

47. Chen TF, Wong YS, Zheng WJ, Bai Y, Huang L. Selenium nanoparticles fabricated in Undaria pinnatifida polysaccharide solutions induce mitochondria-mediated apoptosis in A375 human melanoma cells. Colloid Surf B. 2008;67:26-31.

48. Feng $Y X$, et al. Differential effects of amino acid surface decoration on the anticancer efficacy of selenium nanoparticles. Dalton Trans. 2014;3:1854-61.

49. Daniels LA. Elenium metabolism and bioavailability. Biol Trace Elem Res. 1996:54:185-99.

50. Kennedy GL, Ferenz RL, Burgess BA. Estimation of acute oral toxicity in rates by determination of the approximate lethal dose rather than the LD50. J Appl Toxicol. 1986;6:145-8.

51. Zhou X, et al. Enhancement of endogenous defenses against ROS by supra-nutritional level of selenium is more safe and effective than antioxidant supplementation in reducing hypertensive target organ damage. Med Hypotheses. 2007:68:952-95. 